\title{
Decoding fibre secrets of two jute species
}

Jute is a type of bast fibre plant, of which there are more than hundred species. Jute is used as an affordable natural fibre source for many human purposes. There are only two commercially they cannot be cross-bred. To gain insight into specific traits of these two species, Basic and Applied Research on Jute (BARJ) Project at Bangladesh Jute Research Institute under the leadership of Professor Maqsudul Alam have performe comparative genomics, and through jute DNA sequencing

hat is jute? If you live in sacks and coir mats. Bast is the
the Western world, you fibrous tissue obtained from plant the Western world, you fibrous tissue obtained from plant
may not have come across
stems such as jute, hemp and flax. this plant, but you might have Only two out of more than a hundred it in everyday life. Jute is a type of cultivated. These two species bast fibre plant: the fibres from it have unique fibre characteristics are used in products such as ropes, and other physiological traits, but

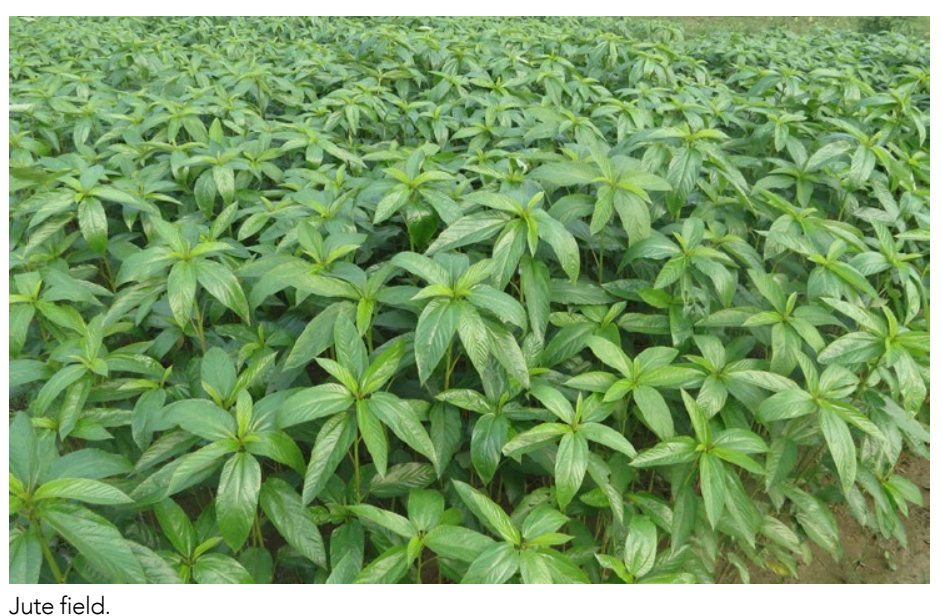

cannot be cross-bred. This leads to enhance the quality of jute fibres tailored breeding, BAR」 Project at Bangladesh Jute Research Institute aimed to decode the genomes (the entire genetic material) of both these species.

\section{WHAT MAKES A}

\section{SPECIES UNIQUE?}

Humans are just one species, and we all have similar characteristic features that allow us to recognise ancher human. However in the close to 400,000 plant species, ere having unique characteristics. That makes a rose unique from a daisy or apple, but also results in variety within a plant family. For example, within the Solanaceae family there are species such as tomato, potato and eggplant, all uniquely differen in their fruits. Yet they have some common characteristics (such as lower structure) that allow these plants to be part of the same family.

The Malvaceae family of plants contains economically importan cacao, and jute. In these species, different plant parts are of economic importance - for example it is the fruit in cacao and okra, whereas it is the fibres surrounding seeds in cotton that are useful to humans. In jute, the bast fibres present in the phloem vascular tissues (that stems form the basis of many largescale jute products. The quality of these bast ilibres determines the strength, and therefore, multiple uses of jute.

There are more than 100 species of jute (Corchorus sp.), yet only two of
them, Corchorus olitorius (tossa jute) and Corchorus capsularis (white jute), are commercially cultivated. Jute has been cultivated since the third millennium $\mathrm{BC}$, by the Indus valley civilisation. Tossa jute originated from Africa and was later brought to the Indian sub-continent, while white jute originated from the Indo-Burma region. Both these species have unique characteristics are trats, controled by genes that

GENES CONTROL PLANT TRAITS DNA is the blueprint of life. The sequence of chemicals (bases) that are arranged in a specific manner in the structure of DNA, makes up a gene. The behaviour of a cell and therefore tissue, is controlled by several genes. All characteristic of a plant, ranging from seed germination, to flower colour, fruit shape, as well as structure of stem fibres, are controlled by gene not a plant can tolerate stresses such as drought extreme temperatures

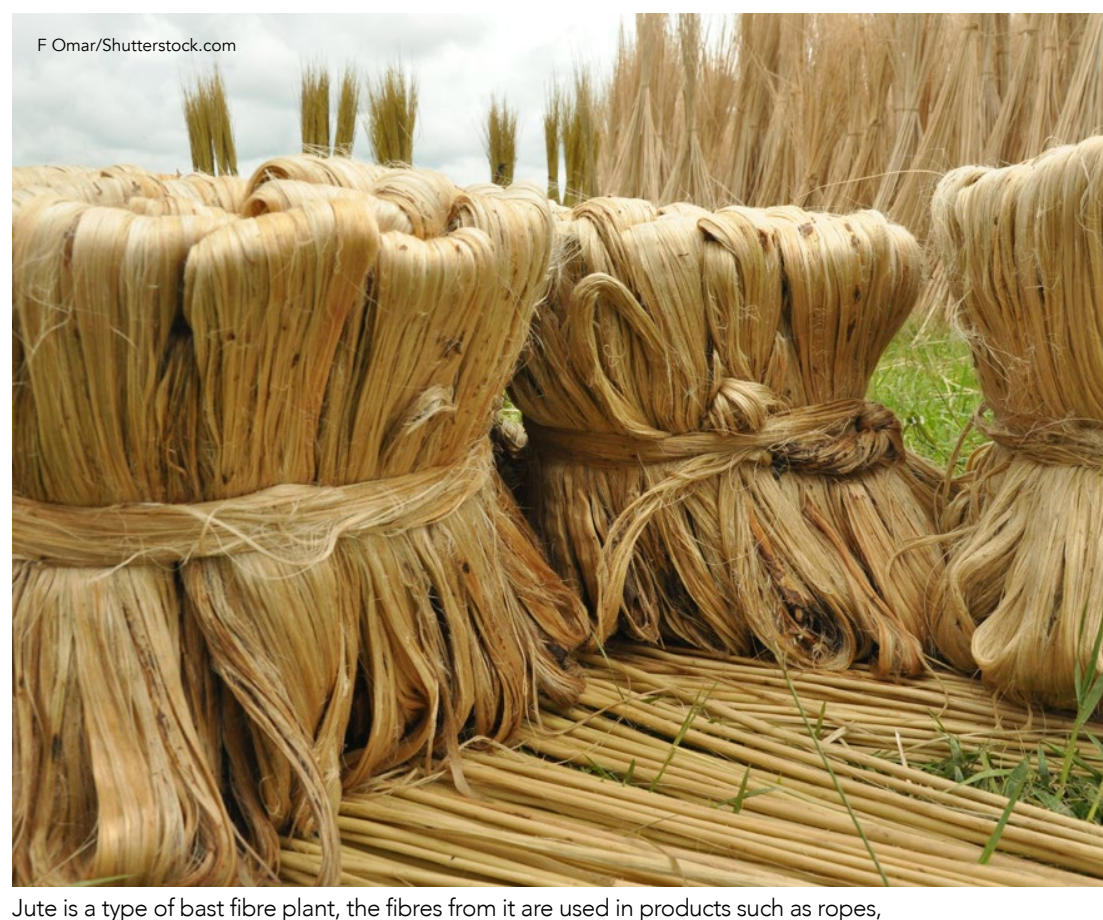

The BARJ Project performed jute genome sequencing of both tossa and white jute.

pathogens, is also determined by species is drought-tolerant but not the products of genes.

For a farmer, getting the most out desirable high yielding, and another species the farmer might want to interbreed these two species so as to get drought-tolerant and high yielding variety of plant. This is enabled by cross-fertilising one species with another (in the same family); in other words, taking pollen from on species and allowing it to fertilis the ovules (eggs) in another species' flower. Cross-fertilising allows the mixing of genes between species, desirable traits.

\section{TO CROSS OR NOT TO CROSS?} The two species of jute that are commercially cultivated cannot crossfertilise. There are many reasons why this might occur, but it implies that through traditional breeding these two species are not compatible. However there are many inheren traits in these individual jute species 


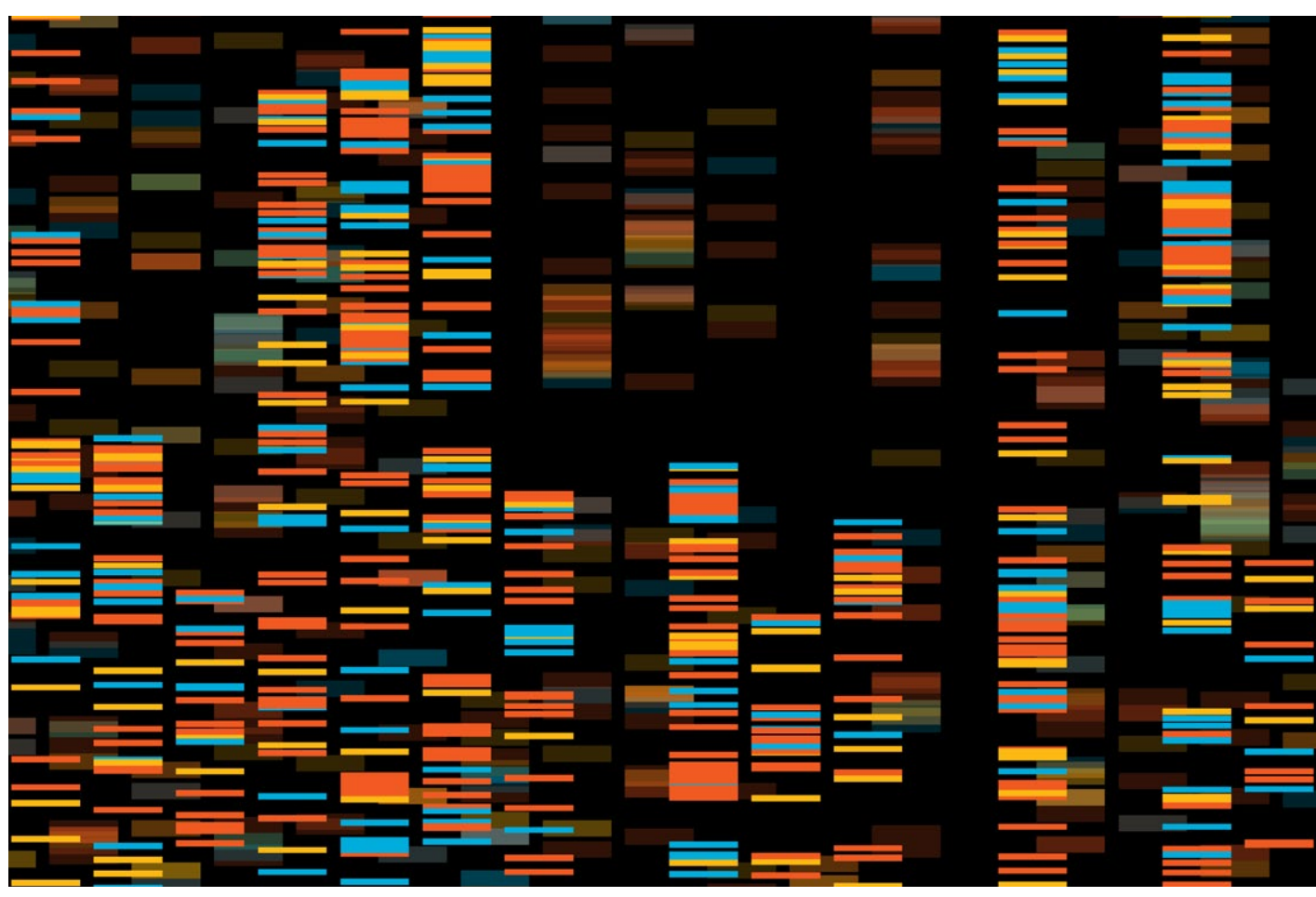

BARJ Project performed jute genome sequencing of both tossa and white jute, which involved decoding of all the genes that are

that, when combined, are favourable to a farmer. For example, tossa jute is less tolerant to flooding, drough and salinity stress, compared with white jute. However, white jute more susceptible to diseases than has affected jute yields due to crops not being tolerant to adverse conditions. With regards to the bast fibres, tossa jute has stronger fibres than white jute that has fibres of finer quality. Therefore

for a jute

combining some

of the desirable

traits would be

beneficial, to
obtain a high-

vielding variety with improved qualty of fibres. So how ifan these breeding is not possible?

\section{DECODING THE MYSTERY} increased knowledge of specific genes in particular plant species would benefit targeted breeding.
BARJ Project performed jute genome sequencing of both tossa and white jute, which involved decoding of all the genes that are present in these plant species. Using highly specialised tools, the genes in both these species were revealed. This allowed comparative genomics of tossa and white jute by obsenving gene structures. In particular, the authors identified

fibre quality. In addition, the authors confirmed stress tolerance of both species, based on the amount of gene products associated with each stress. The study also identified between the jute species.

\section{THE FUTURE OF FIBRE}

Through this comparative genomics bast fibre biogenesis have been identified. This is the next step
towards targeted breeding i.e. choosing of genes that genes regulating bast fibre the breeder. This breakthrough will biogenesis, i.e. genes controlling allow new genetic technologies to high content of lignin in fibre stresses, but also have better cells. Lignin is a biopolymer that quality bast fibres. This would not is abundant in the plant cell wall, only increase the genetic diversity leading to its toughness. The study of jute, but also satisfy the global identified a few lignin-related genes demand for better natural fibres in that confirmed species differences in everyday life. study, severa genes related to are beneficial to bast fibres of jute result from the bere not onlymore tolerant to various
Research Objectives

Decoding the genome of two commercially cultivated jute species to understand the molecular basis of bast fibre iogenesis that gives the facilitation to develop finer fibre bearing jute plant and also foster the application of translational genomics in jute improvement.

\section{References}

slam, M, Saito, J, Emdad, E. et al. (2017) Comparative genomics of two jute species and insight into fibre biogenesis. Nature Plants, 3, 16223. https://doi.org/10.1038/nplants.2016.223

Sarkar, D, Mahato, A, Satya, P. et al. (2017) The draft genome of Corchorus olitorius cv. JRO-524 (Navin). Genomics Data. 12, 151-154. https://doi.org/10.1016/j.gdata.2017.05.007

\section{Personal Response}

\section{What technology can be used in targeted breeding to get the best jute variety?}

II The sexual incompatibility as well as low genetic variability within a single species of jute are the main challenges in developing an improved variety with beneficial traits by conventional breeding. Therefore, the combination of biotechnology, molecular genomics and the development of germplasm variome will lead to a revolution in targeted jute breeding. Screening of phenotypic variation in germplasm and high throughput sequencing data including whole genome, RNA-seq in jute germplasm leads to identify the genetic variants associated with important traits. These variations allow scientists to find the best combint

\section{What challenges do you face to convince a farmer to breed plants in a non-traditional way?}

II Breeding plants other than the traditional way is a mental barrier to farmers as they are highly confused whether it will be beneficial over the traditional way. Farmers become afraid of applying the modern technologies for nontraditional to breed plants due to their educational limitations. They are acquainted with conventional variety and they think that they own the existing variety, why should they risk a new one? Moreover, most of the farmers are small and marginal farmers, so they hesitate to cultivate a new breed that is developed in the non-traditional way.
Therefore, they are not interested in taking extra risks for their crop.

\section{EARJьbiri}

Basic \& Applied Research on Jute 